\title{
Scaling diminution by heterogeneous crystallization in a filtration element integrated with membrane distillation module
}

\author{
Marek Gryta \\ West Pomeranian University of Technology, Szczecin, Institute of Chemical Technology and Environment Engineering, \\ ul. Pułaskiego 10, 70-322 Szczecin, Poland, E-mail: Marek.Gryta@zut.edu.pl
}

\begin{abstract}
Water desalination by membrane distillation is restricted by calcium carbonate precipitation on the membrane surface, what resulted in a progressive decline of the permeate flux. The module rinsing by $\mathrm{HCl}$ solution removed this deposit, however, such operation could cause the membrane wettability, associated with lowering of the permeate flux. This phenomenon was inhibited when the membrane modules with prefiltration element, assembled directly at the inlet to module, were used. The salt deposits were formed mainly on the surface of the filtration element (nets area constituted over $10 \%$ of the membranes area), what protected the membranes assembled inside the module. The filter efficiency decreased when the deposit layer covered the entire surface of pre-filter element, and after a few hours (period of $10-20 \mathrm{~h}$ ) the formation of crystallite on the membrane surface was also observed. Therefore, the formed deposit was systematically removed (at every $5 \mathrm{~h}$ ) from this pre-filter by $3 \mathrm{wt} . \% \mathrm{HCl}$ solutions. The periodical rinsing of nets by acid did not have a negative influence on the membrane
\end{abstract}

Keywords: membrane distillation, capillary module, scaling, water desalination.

\section{INTRODUCTION}

Membrane distillation (MD) is often proposed as a new method for water desalination ${ }^{\mathbf{1}}{ }^{4}$. In this process only water vapour evaporated from the feed is transferred through the porous membranes, what enables the production of the high purity water ${ }^{1,5}$.

The availability of the industrial MD modules is currently one of the limitations for MD process implementation. Flat-sheet membranes in plate and frame modules or spiral wound modules and capillary membranes in tubular modules have been used in various MD studies ${ }^{3-7}$. The design of the MD modules should provide not only good flow conditions, but also has to improve the heat transfer and thermal stability ${ }^{8}$. Several advantages offer the capillary MD modules. The efficiency of these modules was significantly improved when the cross flow or a devices with membranes arranged in a twisted or braided form in the housing were used, ${ }^{9}$. However, a decrease in the module yield due to a progressive wetting of the membranes constitutes a serious problem ${ }^{11}$.

The retention of the gas phase inside the membrane pores is an essential condition of MD process ${ }^{\mathbf{1}}{ }^{12}$. In the direct contact MD (DCMD) a hydrophobic porous membrane separates the hot feed from the cold distillate. As a result of feed heating the $\mathrm{HCO}_{3}$ - ions (present in natural water) undergo the decomposition and a significant amount of calcium carbonate $\left(\mathrm{CaCO}_{3}\right)$ precipitates on the membrane surface'. Deposits formed on the membrane surface causes a progressive wettability of the membrane. This phenomenon is accelerated if salt crystals are also formed inside the pores ${ }^{12}$. As a result of scaling the efficiency of $\mathrm{MD}$ installation can be reduced by more than 50 percent after $50-100 \mathrm{~h}$ of process operation ${ }^{\mathbf{1 1}}$.

The module scaling may be reduced using the appropriate MD process conditions, ${ }^{1,13}$. The $\mathrm{CaCO}_{3}$ precipitation was limited by lowering the feed temperature and by increasing the feed flow rate . Moreover, the $\mathrm{HCO}_{3}$ - ions concentration may be reduced at the pretreatment stage, e.g. by chemical water softening ${ }^{14}$ or by using pressure driven membrane processes ${ }^{5,11}$. On the other hand, an excessively advanced pretreatment system significantly increases the installation costs ${ }^{15}$. An effective solution would be the complete removal of the $\mathrm{HCO}_{3}$ - ions from feed water, which can be achieved by the acidification of water to $\mathrm{pH} 4$. The alkaline deposit formed on the membrane surface can be easily removed by rinsing the module with $2-5$ wt.\% $\mathrm{HCl}$ solutions, which enables to restore the initial MD process yield, ${ }^{9}$. However, in many cases the dissolution of $\mathrm{CaCO}_{3}$ (deposited on the membrane surface) facilitates the penetration of liquid into the pores of hydrophobic membranes, what promotes their wettability ${ }^{11,12}$. Moreover, significant amounts of acids are required for feed acidification and as a result, the amount of salt increased in the retentate discharged to the environment ${ }^{5}$.

The formation of $\mathrm{CaCO}_{3}$ crystals is associated with both the nucleation and growth processes taking place simultaneously ${ }^{17}$. The driving force for these processes is the supersaturation state of the precipitating solutes in the feed. As the saturation ratio increases, the critical nucleus size and critical energy of nucleus formation decrease and a larger number of smaller nuclei is expected to be formed. The critical energy for heterogeneous nucleation (onto membrane surface and/or surface of existing crystals) is usually much lower than for a homogeneous nucleation. As a result of the lower energy barrier, the heterogeneous nucleation and/or crystal growth typically dominates ${ }^{18}$.

The solid $\mathrm{CaCO}_{3}$ can exist in three different polymorphs structures. Calcite, aragonite, and vaterite have trigonal, hexagonal, and orthorhombic structures, respectively ${ }^{19}$. Calcite is thermodynamically the most stable one. Calcite can be identified by its regular structure and defined cubic crystal characteristics, while the irregular structure and dendritic form, are typical for aragonite ${ }^{20}$. The concentration of carbonates, the presence the other salts and water temperature affected the morphology of calcium carbonate crystals ${ }^{19}$. It has been reported that $\mathrm{CaCO}_{3}$ crystals up to $323 \mathrm{~K}$ were entirely composed of calcite, and the ob- 
served particles possessed a rhombohedral shape. At 323 $\mathrm{K}$ calcite particles presented in water showed a tendency of agglomeration with their surface and edges possessing serious defects, and a few number of aragonite particles was also observed. Increasing the water temperature to $353 \mathrm{~K}$ promoted the formation of branch-like aragonite ${ }^{21}$.

The induction time for precipitation is defined as the time that elapsed between the creation of supersaturation state and the first observable change in some physical properties of the precipitation system, e.g. the appearance of crystals or turbidity, a change in the solution conductivity or composition ${ }^{22}$. The induction period of $\mathrm{CaCO}_{3}$ nucleation decreases as the supersaturation increases, but for the low saturation ratios $(5-20)$ the induction period was higher than $30 \mathrm{~min}$. Nason at al, reported that the induction time decreased from 12.9 to $1.1 \mathrm{~min}$ when the saturation ratio increased from 4 to $16^{18}$. Several ions (e.g. $\mathrm{Mg}^{2+}, \mathrm{Ba}^{2+}$ and $\mathrm{SO}_{4}{ }^{2-}$ ) may affect the growth rate of $\mathrm{CaCO}_{3}^{22}$. It can be assumed, that the elimination of membrane scaling is possible when the induction time will be longer than the residue time of feed inside the MD module.

A heterogeneous crystallization performed inside a net filter may decrease the saturation ratio and as a result, the amount of deposit formed on the membrane surface will be reduced ${ }^{14}$. Thus, we can state that the membrane scaling can be limited by the separation of $\mathrm{CaCO}_{3}$ deposit in a pre-filtration element assembled at the inlet of the MD module. The removal of formed deposit from this element (rinsing by $\mathrm{HCl}$ solutions) would not result in the membrane wettability.

In this work a novel design of the MD capillary module with pre-filtration element was applied in order to limit the membrane scaling. The effect of the nets area of this element and its distance from a module inlet on the efficiency of water desalination by MD process has been investigated.

\section{EXPERIMENTAL}

The investigations of water desalination by MD process were performed using the installation presented schematically in Fig. 1.

The installation consisted of two thermostatic cycles (feed and distillate) that were connected to a membrane module. A net filter (50 mesh) was installed upstream of the feed tank. The feed was supplied inside the membrane capillaries (tube-side), whereas the distillate flowed on the shell-side of the MD module. The parameters of used modules were presented in Table 1. Hydrophobic capillary polypropylene membranes (Accurel S6/2 PP, Membrana, Germany), with the outside/inside diameter equal to $d_{\text {out }} / d_{\text {in }}=2.6 \mathrm{~mm} / 1.8 \mathrm{~mm}$, were assembled inside these modules. The applied membranes have pores sizes with the maximum and nominal diameter of $0.55 \mu \mathrm{m}$ and 0.22 $\mu \mathrm{m}$, respectively, and the porosity of $73 \%$ (manufacturer's data). The inlet temperatures of distillate $(293 \mathrm{~K})$ and feed $(353 \mathrm{~K})$ were constant for all the experiments. The temperatures were measured using thermometers with $\pm 0.2 \mathrm{~K}$ accuracy.

Tap water (alkalinity $2.1 \mathrm{mmol} \mathrm{HCO}_{3}-\mathrm{dm}^{-3}$ ) or tap water with the addition of $\mathrm{NaHCO}_{3}$ and $\mathrm{CaCl}_{2}$ (mole ratio 2:1,

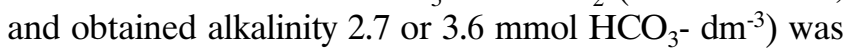

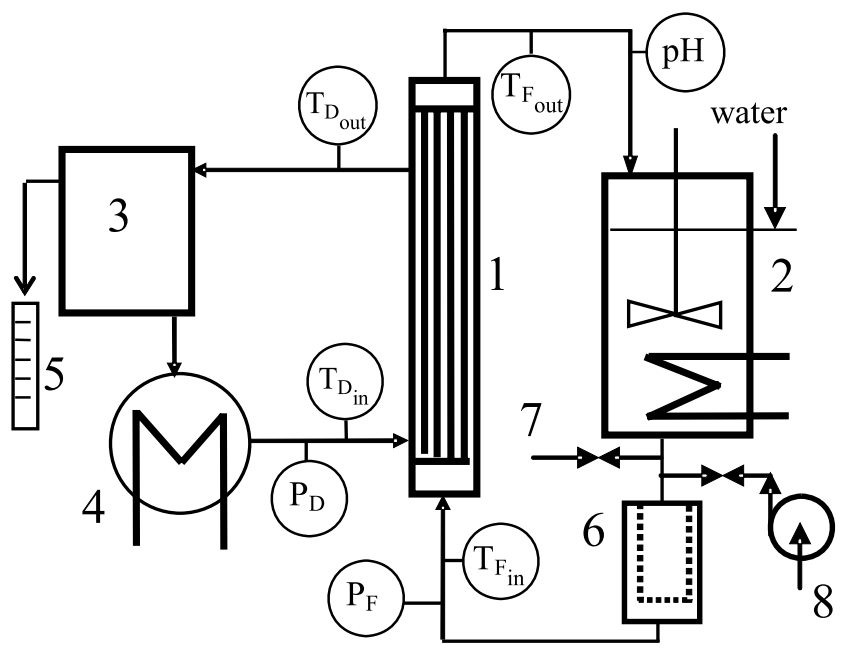

Figure 1. MD experimental set-up. 1 - MD module, 2 - feed tank with heating element, 3 - distillate tank, 4 cooling, 5 - measurement cylinder, 6 - net filter, 7 - retentate drainage, 8 - dosing system of $\mathrm{HCl}$ solution, $\mathrm{P}_{\mathrm{D}}, \mathrm{P}_{\mathrm{F}}-$ manometers, $\mathrm{T}_{\text {Din }}, \mathrm{T}_{\text {Dout }}, \mathrm{T}_{\text {Fin }}$ and $\mathrm{T}_{\text {Fout }}$ - thermometers, $\mathrm{pH}$ - pehameter

Table 1. The parameters of used MD modules

\begin{tabular}{|l|c|c|c|c|}
\hline Module & $\begin{array}{c}\text { Shell diameter } \\
{[\mathrm{m}]}\end{array}$ & $\begin{array}{c}\text { Length } \\
{[\mathrm{m}]}\end{array}$ & $\begin{array}{c}\text { Number } \\
\text { of capillaries }\end{array}$ & $\begin{array}{c}\text { Area } \\
{\left[\mathrm{m}^{2}\right]}\end{array}$ \\
\hline $\mathrm{M} 1-\mathrm{M} 3$ & 0.012 & 1.07 & 1 & 0.0065 \\
\hline $\mathrm{M} 4$ & 0.025 & 0.56 & 28 & 0.0887 \\
\hline $\mathrm{M} 5$ & 0.013 & 0.25 & 9 & 0.0127 \\
\hline $\mathrm{M} 6$ & 0.012 & 1.06 & 1 & 0.0060 \\
\hline
\end{tabular}

continuously dosed to feed tank (volume of $1.5 \mathrm{dm}^{3}$ ). The retentate was removed from the feed tank (Fig.1, valve 7) when $0.5 \mathrm{dm}^{3}$ of the permeate was collected $(25 \%$ of water recovery), and subsequently the tank was refilled with fresh portion of feeding water. In the case when the M4 module was used a larger feed tank $\left(7 \mathrm{dm}^{3}\right)$ and larger pumps were applied, but $25 \%$ coefficient of water recovery was maintained.

The anion and cation concentrations were measured using an ion chromatography method with conductivity detector (850 Professional IC, Herisau Metrohm Switherland). The separation of anions was achieved on $1.7 \times 3.5 \mathrm{~mm}$ Metrosep RP guard column in series with a 250x4.0 mm Metrohm A Supp5-250 analytical column. For cations separation a $150 \times 4.0 \mathrm{~mm}$ Metrosep C2-150 analytical column was used. The used tap water had the following average ionic composition (ppm): $\mathrm{Na}^{+}-28.52$, $\mathrm{Mg}^{2+}-17.95, \mathrm{Ca}^{2+}-64,86, \mathrm{~K}^{+}-6.37, \mathrm{Br}^{-}-0.13, \mathrm{SO}_{4}{ }^{2-}$ $-102.35, \mathrm{NO}_{3}^{-}-1.24$ and 54.61 chloride ions.

The morphology and composition of the deposit layer formed on the membrane surface were studied using a scanning electron microscopy (SEM) coupled with energy dispersion spectrometry (EDS). The electrical conductivity of the used waters and $\mathrm{pH}$ were measured with a $6 \mathrm{P}$ Ultrameter (Myron L Company).

\section{RESULTS AND DISCUSSION}

In the studies performed the period of feed flow through the MD module was shorter than $2 \mathrm{~s}$, what decreased the possibility of $\mathrm{CaCO}_{3}$ crystallization. However, the permeate flux constitutes only $2-3$ vol.\% of the feed stream 
flowing through the module in MD process. Thus, in order to achieve higher degrees of water recovery the feed was reheated and recycled to the module during the MD process, what prolonged the residence time of water in the MD installation. In these studies the recovery of water amounted to $25 \%$, and was achieved after about $2 \mathrm{~h}$ of installation operation (M1 - M3 modules). This period was found to be sufficient for the formation of $\mathrm{CaCO}_{3}$ crystallites $^{18,22}$.

Moreover, a low ratio of the permeate/feed volume caused that the increase in the feed concentration inside the MD module was small, and the supersaturation state was mainly generated by increasing the feed temperature inside the heat exchanger. For this reason, the crystallization of $\mathrm{CaCO}_{3}$ (reduction of the saturation ratio) before the inlet of MD module may prevent the formation of deposit on the membrane surface.

The obtained results of MD investigations confirmed that the net filter assembled at the module inlet had a significant influence on the rate of the permeate flux decline (Fig. 2). In the case of the M1 module (without the filter) the permeate flux decreased from 774 to 703 $\mathrm{dm}^{3} \mathrm{~m}^{-2} \mathrm{~d}^{-1}$ during $58 \mathrm{~h}$ of the MD process operation (line 1). The application of filter allowed a $2-3$ fold decrease in the magnitude of this decline (Fig. 2 - lines 2 and 3).

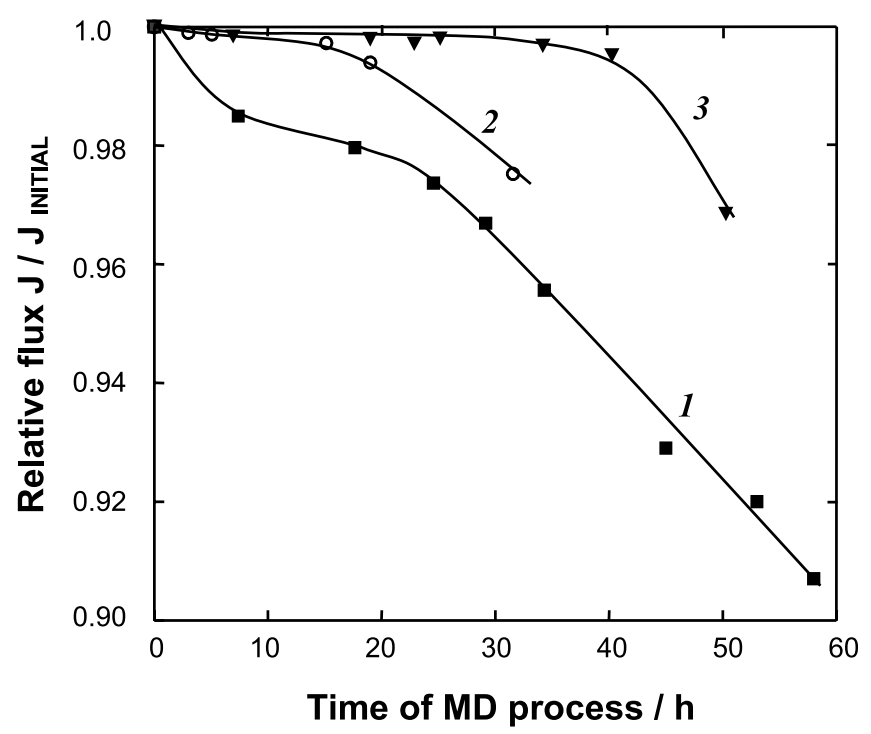

Figure 2. The changes of the relative permeate flux during MD of tap water. ( $\mathbf{a})$ without filter - module M1; (O) net filter assembled in the distance of $80 \mathrm{~cm}$ from the module inlet - module M2. ( $\nabla)$ net filter assembled $5 \mathrm{~cm}$ from the module inlet - module M3. Process parameters: feed velocity $1.02 \mathrm{~m} \mathrm{~s}^{-1}$, $\mathrm{T}_{\text {Fin }}=358 \mathrm{~K}, \mathrm{~T}_{\text {Fout }}=348 \mathrm{~K}$, and filter area $0.0015 \mathrm{~m}^{2}$

The SEM examinations of the membrane samples, collected from M1 - M3 modules, showed that the several crystallites were deposited on the membrane surfaces. The SEM-EDS analysis revealed that apart from a significant amount of $\mathrm{Ca}$, the observed deposit also contained $\mathrm{Mg}, \mathrm{Si}$, $\mathrm{Al}, \mathrm{Fe}, \mathrm{Cl}$ and $\mathrm{S}$. The amount of magnesium in the crystals was about $1-1.5 \%$. The observed deposit covered a part of the membrane surfaces, which reduced the membrane permeability and increased the temperature polarisation, the result of which was a decline of the permeate flux ${ }^{\mathbf{1 1}}$. However, the amount of scale deposited on the membrane surface was different in each studied case, resulting in significant differences in the rate of decline of the modules yield (Fig. 2). The largest amounts of deposit were formed in the M1 module, which was working without the filter (Fig. 3).

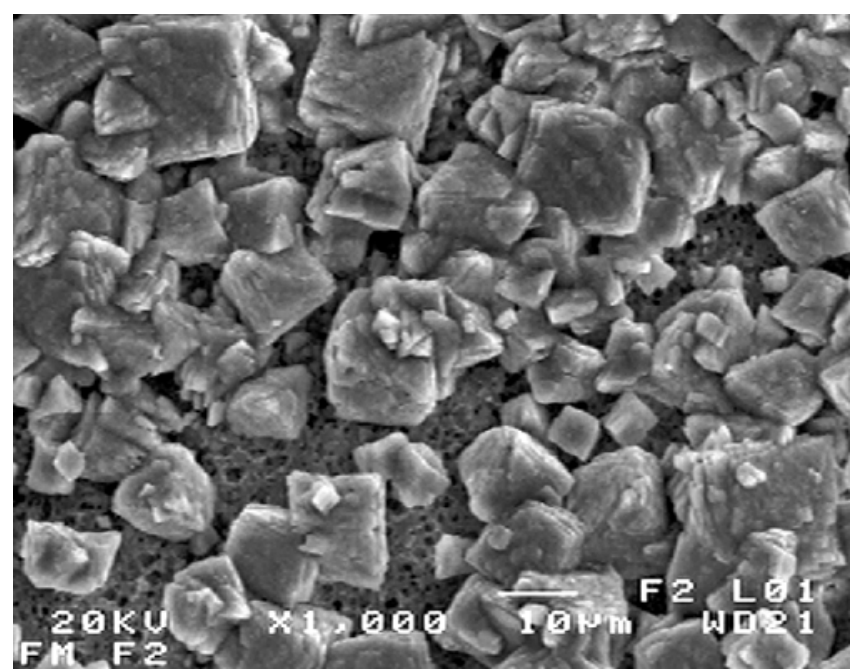

Figure 3. SEM images of calcium carbonate scale deposited on the membrane surface $(10 \mathrm{~cm}$ from the module inlet). M1 module without a net filter. Feed: tap water

The SEM investigations confirmed that the amount of deposit formed within the interior of MD module can be significantly decreased when the filter element is assembled at the module inlet. The net filter worked as a heterogeneous crystallizer and a large amount of the $\mathrm{CaCO}_{3}$ was deposited on the net surface (Fig. 4).

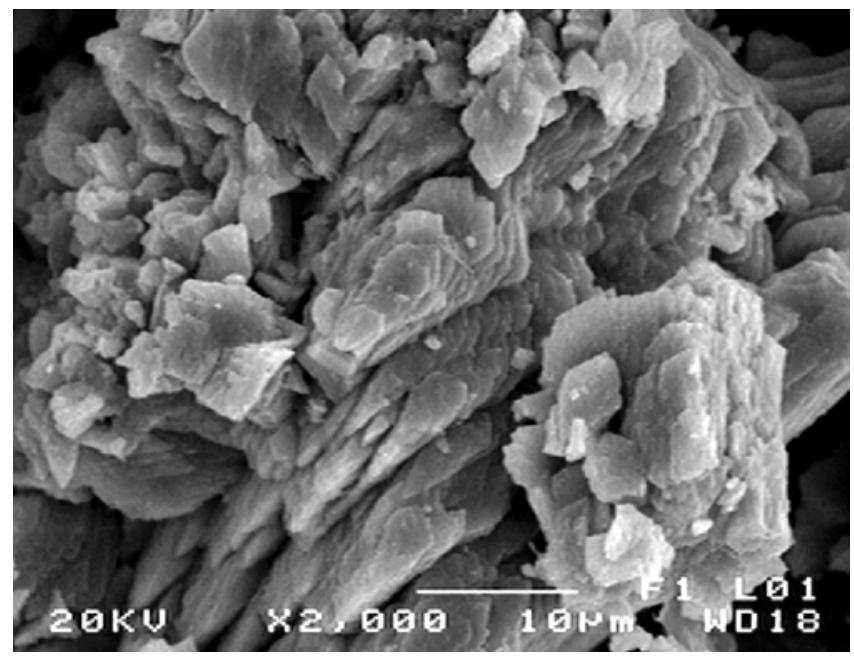

Figure 4. SEM images of calcium carbonate scale deposited inside the net filter

A growth of forming crystallites to $10-20 \mu \mathrm{m}$ decreased the rate of heterogeneous crystallization ${ }^{17}$, what reduced the filter efficiency and the crystallites were also deposited on the membrane surface. However, the SEM investigations revealed that the $\mathrm{CaCO}_{3}$ deposit crystallized mainly in the vicinity of the modules inlet and the majority of the membrane surface was free of deposit (Fig. 5 ). For this reason the decrease in the permeate fluxes for the M2 - M3 modules was significantly smaller than that observed for the M1 module, which was used without the net filter (Fig. 2). 

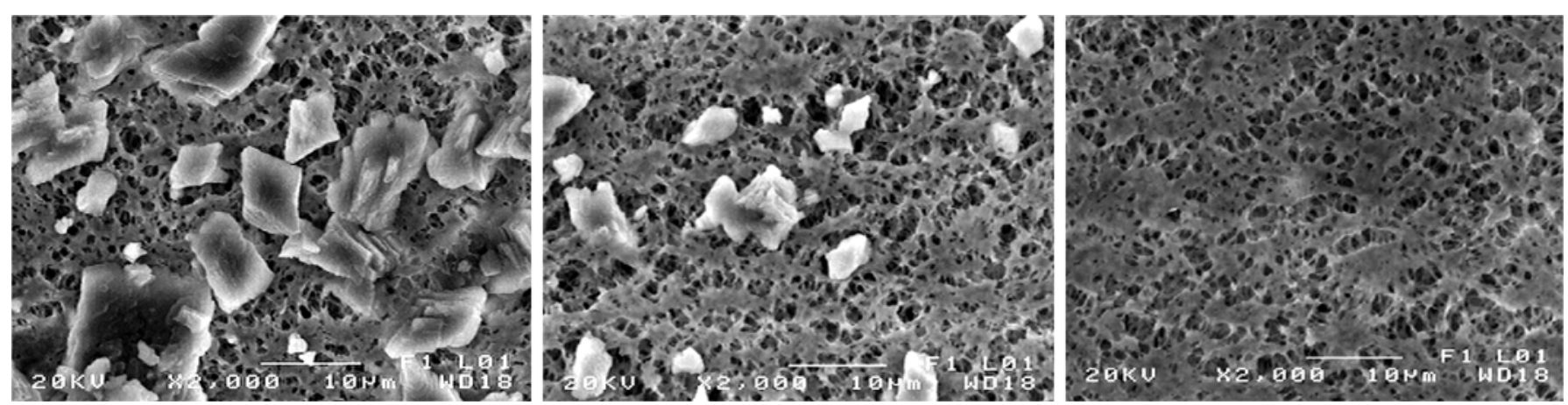

Figure 5. SEM images of calcium carbonate scale deposited inside the M3 module. Distance from the module inlet: A) $4 \mathrm{~cm}$, B) $20 \mathrm{~cm}$, and C) $90 \mathrm{~cm}$

A distance between the filter and the inlet of the MD module was found to have a significant influence on the obtained results. An increase of this distance from $5 \mathrm{~cm}$ (M3 module) to $80 \mathrm{~cm}$ (M2 module) caused that the permeate flux was reduced by a similar magnitude over shorter period of time (Fig. 2). SEM investigations indicated that more of deposit was formed within the interior of the M2 module than the amounts presented in Fig. 5, although, the crystallite shapes were similar in both cases. Most probably, extension of distance between the filter and module caused that new nucleolus of crystals may be formed before the feed will flow into the module.

The application of the net filter affected not only the amount, but also the shape of formed crystallites (Figs. 3 and 5). An image in Fig. 3 reveals the formation of deposit with the regular structure of calcium carbonate crystals, having unique characteristic of calcite. A part of formed crystals have distorted the edges and the surfaces, what resulted from presence of $\mathrm{Mg}^{2+}$ ions and high temperature $^{21}$ 22 . A SEM image in Fig. 5 (filter was used) shows besides calcite also irregular crystals, which indicate the presence of aragonite ${ }^{13,20}$. The supersaturation is known to affect the nucleation and growth steps of $\mathrm{CaCO}_{3}$, and calcite formation is favoured under the conditions of higher supersaturation conditions. The formation of aragonite at higher temperatures was attributed to a decrease in the supersaturation conditions ${ }^{21}$. These results confirmed that the saturation ratio was decreased when the pre-filtration element was used.

The image in Figs. 3 and 4 also demonstrates the different structures of calcium carbonate crystals, although the saturation ratio was similar. This effect resulted most probably from the influence of feed temperature (deposit layer). A vigorous mixing of liquid was inside the filter, and the temperature of deposits layer was closed to feed bulk temperature (e.g. $353 \mathrm{~K}$ ). This favours the formation of aragonite, and both the aragonite and calcite were crystallized on the surface of nets. Whereas, the temperature of layer adjacent to the membrane inside the M1 module is lower than the bulk temperature (as a result of heat and mass transfer through the membrane), therefore, the crystallization of calcite was favoured. For this reason, we can observe more crystallites with the regular structure (Fig. 3).

A reduction of the residence time of the feed inside the MD installation may decrease the amount of formed deposit. Therefore, a M4 module (larger membranes area) was employed in further studies, which allowed to shorten the MD process time from 2 hours to less than 1 hour.
However, the results presented in Fig. 6 indicate that the efficiency decrease still took place. Probably, the rate of decline of the permeate flux could be smaller in the case when the feed residence time did not exceed one minute ${ }^{18}$. However, the achievement of appropriately high value of the coefficient of water recovery excludes the possibility of application of such short residence time in the MD installation.

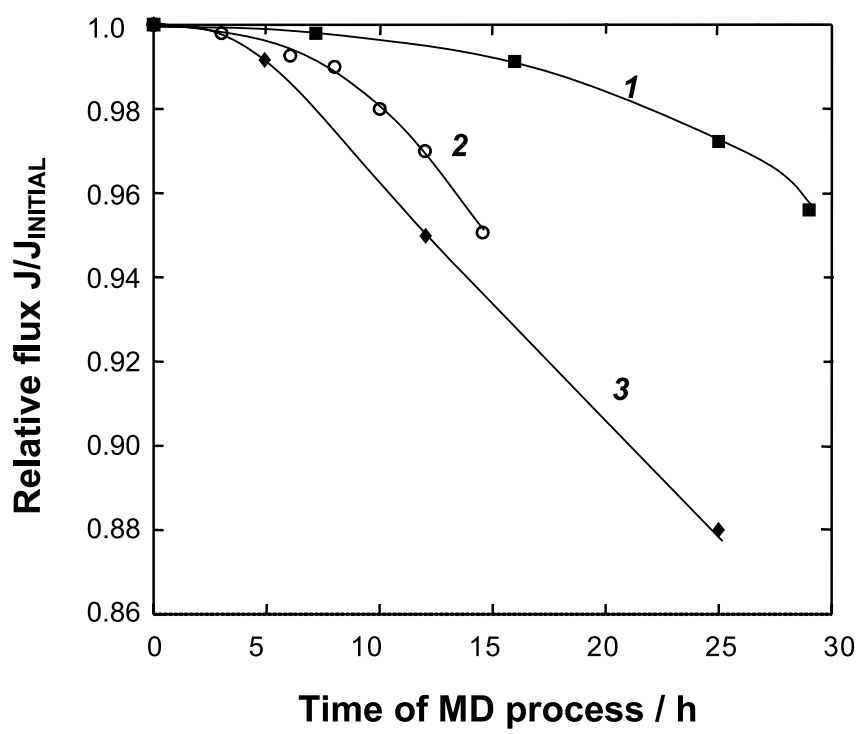

Figure 6. Influence of the filter area on the relative permeate flux during the MD process of tap water. Nets area/membranes area: $(1, \mathbf{\square})-21 \%,(2,0)-10 \%$, $(\diamond)-4.8 \%$. M4 module. Filter assembled $5 \mathrm{~cm}$ from the module inlet. Feed velocity $1.3 \mathrm{~m} \mathrm{~s}^{-1}$, $\mathrm{T}_{\text {Fin }}=358 \mathrm{~K}, \mathrm{~T}_{\mathrm{Fout}}=349 \mathrm{~K}$

A significant influence on the filter efficiency has the area of assembled nets. More active sites can be achieved for the heterogeneous crystallization by the application of the filters with a large area, hence, the protection time of the membranes is prolonged and the module efficiency decreased slower (Fig. 6). However, even the application of filter with area corresponding to $21 \%$ of the membrane areas did not allow to obtain a sufficiently long time of module exploitation.

The amount of precipitated $\mathrm{CaCO}_{3}$ depended on the concentration of carbonates in the feed, thus a decline of the MD module efficiency was progressively higher along with an increase in the feed hardness under the some conditions of process (Fig.7). Moreover, the M5 module efficiency decreased significantly faster than that observed in the case of modules M1-M3 (Fig.2). This resulted from the fact that the M5 module was four times shorter (Table 1), 
and assumption that a similar surface of the module inlet area was covered by deposit, the ratio of fouled area/total module area increased faster for M5 module. Moreover, 9 capillaries were assembled inside the M5 module, thus the feed linear velocity was reduced 9 times. The reduction of the flow velocity significantly increases the negative effects of scaling?.

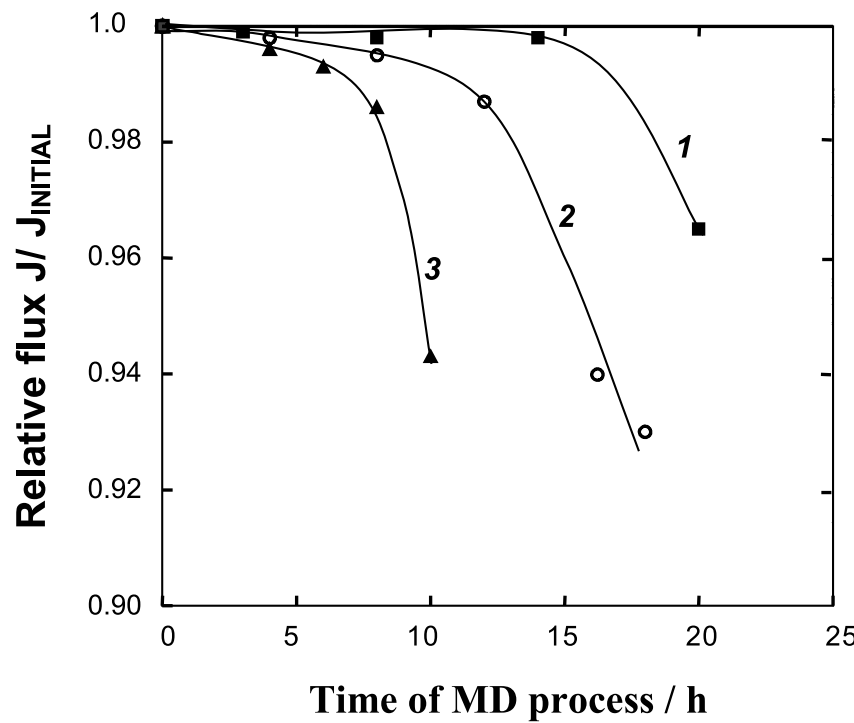

Figure 7. Influence of the water hardness on the relative permeate flux during MD process. Initial water alkalinity: $(1, \mathbf{-})-2.1 \mathrm{mmol} \mathrm{HCO}_{3}-\mathrm{dm}^{-3},(2, \mathrm{O})-$ 2.7 mmol $\mathrm{HCO}_{3}-\mathrm{dm}^{-3},(3, \bullet)-3.6$ mmol $\mathrm{HCO}_{3}-$ $\mathrm{dm}^{-3}$. M5 module. Filter $\left(0.0025 \mathrm{~m}^{2}\right)$ assembled 5 $\mathrm{cm}$ from the module inlet. Feed velocity $0.11 \mathrm{~m} \mathrm{~s}^{-1}$, $\mathrm{T}_{\text {Fin }}=358 \mathrm{~K}, \mathrm{~T}_{\text {Fout }}=348 \mathrm{~K}$

The results presented previously indicate that the application of the pre-filter element allows to eliminate the formation of deposit on the membrane surface only over limited time, that was about $7-20 \mathrm{~h}$ for the cases under study and tap water as a feed. The efficiency of the filter operation could be retained when the deposit accumulated on the nets surface would be removed in a shorter time. This thesis was completely confirmed in further studies with M6 module used for purification of tap water. Periodically, at every $5 \mathrm{~h}$, a $3 \mathrm{wt} . \% \mathrm{HCl}$ solutions was dosed into the filter interior. The flow of acid solution was stopped when the $\mathrm{pH}$ of the feed at the module outlet decreased to value of 4 . The results presented in Fig. 8 indicate that a periodical cleaning of the filter surface allowed to maintain the MD module efficiency at a high level during a long-term exploitation. The SEM investigations confirmed that the membrane surface was free of scale, and only a few deposits were observed.

\section{CONCLUSIONS}

The application of pre-filtration element assembled directly to the MD module inlet allows to limit the amounts of precipitates deposited on the membrane surface during the desalination of natural water by MD process. The efficiency of this system was found to decrease along with an increase of distance of pre-filter element from the module inlet.

Deposit formed inside the pre-filter element should be systematically removed, e.g. by dosing a portion of $3 \mathrm{wt}$. $\% \mathrm{HCl}$ solutions into the filter. Rinsing of the filter is

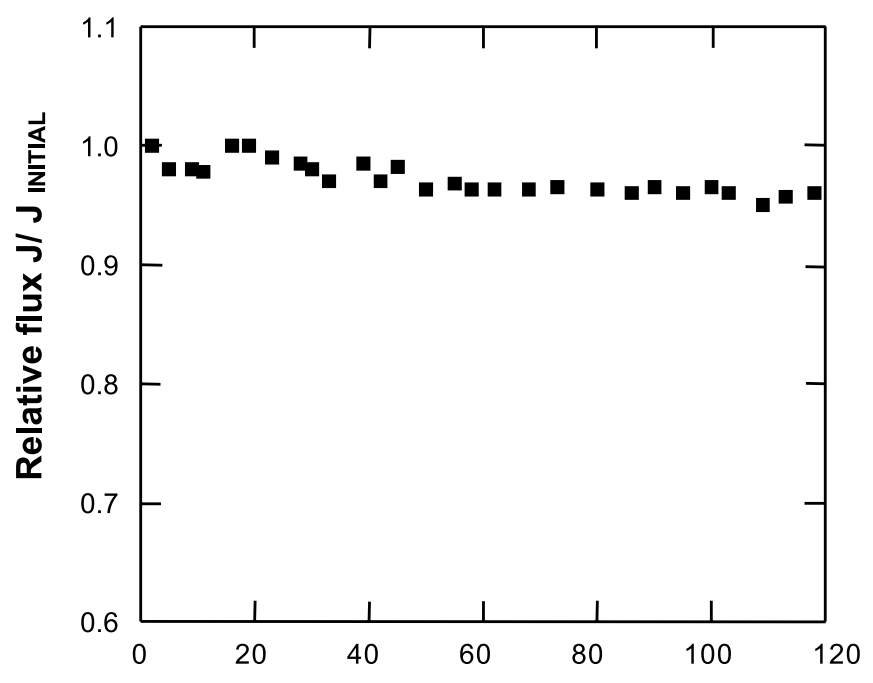

Time of MD process / $\mathrm{h}$

Figure 8. Variation of the relative permeate flux during MD of tap water with net filter rinsed by 3 wt. $\% \mathrm{HCl}$ solutions (every $5 \mathrm{~h})$. M6 module. Filter $\left(0.0015 \mathrm{~m}^{2}\right)$ assembled $5 \mathrm{~cm}$ from the module inlet. Feed velocity $1.1 \mathrm{~m} \mathrm{~s}^{-1}, \mathrm{~T}_{\mathrm{Fin}}=358 \mathrm{~K}, \mathrm{~T}_{\mathrm{Fout}}=345 \mathrm{~K}$

completed when the $\mathrm{pH}$ of the effluent from the MD module decreased to value of 4 .

The period between consecutive rinsing operations of the pre-filter is dependent on the several factors, such as a water hardness level, parameters of MD process and the residence time of the feed inside the MD installation. On the basis of the obtained results it can be assumed, that this period would be in the range of $2-5 \mathrm{~h}$.

The $\mathrm{CaCO}_{3}$ crystallization (mainly calcite) inside the pre-filter affected not only the amount but also the structures of crystallites formed on the membrane surface. Moreover, decrease of the supersaturation conditions favored the aragonite formation.

\section{ACKNOWLEDGEMENTS}

The Polish State Committee for Scientific Research is acknowledged for the support of this work (2006 - 2009).

The author would like to thank the Prof. Tai-Shung Chung and Dr May May Teoh from National University of Singapore and $\mathrm{A}^{*}$ Star for their useful suggestions.

\section{LITERATURE CITED}

1. El-Bourawi, M.S., Ding, Z., Ma, R., \& Khayet, M. (2006). A framework for better understanding membrane distillation separation process. J. Membr. Sci., 285, 4 - 29, DOI: 10.1016/j.memsci.2006.08.002.

2. Wang, J., Fan, B., Luan, Z., Qu, D., Peng, X. \& Hou, D. (2008). Integration of direct contact membrane distillation and recirculating cooling water system for pure water production. J. Clean. Prod. 16, 1847 - 1855. DOI: 10.1016/ .jclepro.2007.12.004.

3. Xu, Y., Zhu, B. \& Xu, Y. (2006). Pilot test of vacuum membrane distillation for seawater desalination on a ship. Desalination 189, 165 - 169. DOI: 10.1016/j.desal.2005.06.024

4. Tomaszewska, M. (2007). Industrial wastewater treatment by means of membrane techniques, Pol. J. Chem. Tech. 9(3) 138 - 142. DOI: 10.2478/v10026-007-0074-z

5. Karakulski, K. \& Gryta, M. (2005). Water demineralisation by NF/MD integrated processes. Desalination 177, 109119. DOI: 10.1016/j.desal.2004.11.018. 
6. Bonyadi, S. \& Chung, T.S. (2009). Highly porous and macrovoid-free PVDF hollow fiber membranes for membrane distillation by a solvent-dope solution co-extrusion approach. J. Membr. Sci. 331, 66 - 74, DOI:10.1016/ j.memsci.2009.01.014.

7. Tomaszewska, M. \& Mientka, A.(2008). Separation of $\mathrm{HCl}$ from the mixture of $\mathrm{KCl}$ and $\mathrm{HCl}$ using membrane distillation. Pol. J. Chem. Tech. 10(2) 27 - 32. DOI: 10.2478/ v10026-008-0024-4.

8. Al-Obaidani, S., Curcio, E., Macedonio, F. \& Di Profio, G. (2008). Potential of membrane distillation in seawater desalination: Thermal efficiency, sensitivity study and cost estimation. J. Membr. Sci., 323, 85 - 93. DOI: 10.1016/ j.memsci.2008.06.006.

9. Gryta, M. (2008). Alkaline scaling in the membrane distillation process. Desalination 228, 128 - 134. DOI: 10.1016/ j.desal.2007.10.004.

10. Li, B. \& Sirkar, K. K., (2004). Novel membrane and device for direct contact membrane distillation-based desalination process, Ind. Eng. Chem. Res. 43, 5300 - 5309.

11. Gryta, M. (2008). Fouling in direct contact membrane distillation process. J. Membr. Sci. 325, 383 - 394. DOI: 10.1016/j.memsci.2008.08.001.

12. Gryta, M. (2007). Influence of polypropylene membrane surface porosity on the performance of membrane distillation process, J. Membr. Sci. 287, 67 - 78. DOI: 10.1016/ j.memsci.2006.10.011

13. Euvrard, M, Membrey, F., Filiatre, C. \& Foissy, A. (2004). Crystallization of calcium carbonate at a solid/liquid interface examined by reflection of a laser beam. J. Cryst. Grow. 265, 322 - 330. DOI: 10.1016/j.jcrysgro.2004.01.041

14. Gryta, M. (2008). Chemical pretreatment of feed water for membrane distillation. Chem. Pap. 62, 100-105. DOI: 10.2478/s11696-007-0085-5

15. Karakulski, K., Gryta, M. \& Sasim, M. (2006). Production of process water using integrated membrane processes. Chem. Pap. 60, 416 - 421. DOI: 10.2478/s11696-006-0076-y.

16. Scott, K. (1997). Handbook of industrial membranes, Kidlington (UK): Elsevier.

17. Al Nasser, W.N., Shaikh, A., Morriss, C., Hounslow, M.J. \& Salman, A.D. (2008). Determining kinetics of calcium carbonate precipitation by inline technique. Chem. Eng. Sci. 63, 1381 - 1389. DOI: 10.1016/j.ces.2007.07.051.

18. Nason, J.A. \& Lawler, D.F. (2008). Particle size distribution dynamics during precipitative softening: constant solution composition. Wat. Res. 42, 3667 - 3676, DOI: 10.1016/ j.waters.2008.05.016.

19. Koyuncu, I. \& Wiesner, M.R. (2007). Morphological variations of precipitated salts on NF and RO membranes, Environ. Eng. Sci. 24, 602 - 614. DOI: 10.1089/eee.2006.0114.

20. Marin-Cruz, J., Garcia-Figueroa, E., MirandaHernandez, M. \& Gonzalez, I. (2004). Electrochemical treatments for selective growth of different calcium carbonate allotropic forms on carbon steel. Wat. Res. 38, 173 - 183, DOI:10.1016/j.waters.2003.08.023.

21. Altay, E., Shahwan, T. \& Tanaglu, M. (2007). Morphosynthesis of $\mathrm{CaCO}_{3}$ at different reaction temperatures and the effects of PDDA, CTAB, and EDTA on the particle morphology and polymorph stability. Pow. Technol. 178, 194 - 202. DOI:10.1016/j.powtec.2007.05.004.

22. Chen, T., Neville, A. \& Yuan, M. (2006). Influence of $\mathrm{Mg}^{2+}$ on $\mathrm{CaCO}_{3}$ formation-bulk precipitation and surface deposition. Chem. Eng. Sci. 61, 5318 - 5327, DOI: 10.1016/ j.ces.2006.04.007 